\title{
Recent news stories of interest
}

\author{
Journal of Building Appraisal (2006) 2, 178-182. doi:10.1057/palgrave.jba.2950048
}

\section{BUILDING FAILURES}

\section{Big Dig problems following fatal accident}

Following a fatal accident, Massachusetts' governor has become involved in the inspections of the tunnel road system that replaced the former overhead road system that ran across the centre of Boston, and which included Interstate 93. The progress of the cut and fill tunnelling became known as the Big Dig. The top of one of the tunnels was lined with concrete panels, and it was one of these that fell upon a car killing one of the occupants. The three-ton ceiling panels that collapsed were part of a false ceiling used to improve ventilation in the tunnel, as well as to protect the structure in case of fire or other catastrophe. The concrete ceiling panels were secured by anchoring bolts fixed to the roof with epoxy adhesive.

The Governor signed emergency legislation that gave him responsibility for tunnel inspections that had previously been overseen by the Massachusetts Turnpike Authority. The law also enables him to decide when it will be safe for the public to use the tunnels. Inspectors looking for design or construction flaws have focused on bolts that hold the ceiling panels in. The Governor put the total number of potential problems at 84 in the tunnel where the fatality occurred. He said two adjoining sections of the tunnel, as well as traffic ramps, had another 278 possible defects. Inspections have found at least 242 points where bolts were separating from the tunnel roof. In addition, there were 401 potential trouble spots in neighbouring tunnels, but none was especially worrisome because those tunnels have different designs with greater redundancy. The ceiling panels in those tunnels are also much lighter than the three-ton concrete panel that fell on 10th July, 2006. The project took roughly 20 years of planning, design and construction, and costs increased from initial estimates of \$2.6-\$14.6bn.

\section{Ascot runs into problems}

The perceived success of the two-year $£ 185 \mathrm{~m}$ refurbishment of the Royal Ascot racecourse has been tarnished by over a 1,000 complaints about visibility from the new grandstand. The grandstand has seating for 30,000 people and there are also 272 private boxes. The refurbishment was completed on time and within budget.

\section{Reduction in annual injuries on building sites}

Figures released by the Health and Safety Executive show the rate of major injuries reduced by 5 per cent in 2005/2006 from the previous period. Fifty-nine construction workers died in the year period of the statistics, a reduction from the previous period's total of 69.

\section{CONSTRUCTION}

\section{Urban sewage design practice}

CIRIA's new guidance, designing for exceedance in urban drainage - good practice, provides advice for the design and management of urban sewerage and drainage systems.

It looks at how to reduce the impacts that arise when flows occur that exceed their capacity and explains how systems can be designed to safely and sustainably accommodate excess water during extreme weather events.

It aims to improve engineers, planners and designers' appreciation of the risks associated with urban drainage systems and how these risks may be mitigated.

Heat waves or prolonged periods of drought followed by intense rainfall can cause localised flash flooding. In the event of extreme rainfall, the capacities of sewers and other drainage systems can be tested to their limits. If drainage capacity is exceeded, surface flooding may occur. 
Excess water is conveyed above ground and will travel along streets and paths, between and through buildings and across open space. Indiscriminate flooding of property can occur when this flow of water is not controlled.

Experience has shown that much of the recorded flooding in urban areas is attributable to the passage of above ground surface flow. Much, however, can be done to mitigate the effects if surface flood flow is managed proactively. Recognising the importance of flood pathways along highways and other routes, and the storage of water in low spots, is the first step to better management. Through good design, a second important step is to direct flood flows along routes where the risk to health and safety is minimal.

Designing for exceedance in urban drainage-good practice (C635) is available to buy or download from CIRIA.

\section{Time for change?}

The flushing toilet was invented by John Harrington in 1597. The S bend, whose trap blocked smells, was added in the 1700s when Alexander Cummings (a watch maker) obtained the first patent for a flushing toilet. Thomas Crapper (1836-1910) patented three different types of water closet including the silent valveless water waste preventer. The flushing toilet uses about ten times as much drinking water to flush away the water that has been drunk.

\section{Government building plans result in rising costs}

Tender prices for construction work are expected to rise significantly faster than inflation over the next five years, according to a report published by the Building Cost Information Service (BCIS) of the RICS. Tender prices are expected to rise by more than two-and-a-half times the rate of inflation over the next five years, rising by 33 per cent against a background of 12 per cent general inflation. New work construction output is expected to rise above its long-term annual trend rate over the next five years, the divergence increasing with time over the forecast period. This, together with pressure from input cost rises (labour, materials etc), is expected to lead to tender prices rising significantly above inflation over each year of the forecast.

Pressures from input costs include those from wage awards, which are expected to continue to outstrip inflation throughout the forecast period. The main stimulus for growth is likely to come from the private commercial sector, through an improved offices subsector and increased Private Finance Initiative (PFI) work in the education and health sectors. For example, the UK Government recently gave the green light to $£ 1.5 \mathrm{bn}$ of PFI schemes in the health sector.

The infrastructure sector will aid growth, with a recovery in highway agency work and new investment programmes in the water and electricity industries. Olympic-based construction will start to kick in from 2007, affecting mainly the infrastructure and entertainment sectors.

The public housing sector is set to have significant year-on-year growth with the Government committed to significantly increasing the supply of new social housing, but this sector only represents a small percentage of total construction output.

\section{Construction (Design and Management) changes}

The new Construction (Design and Management) regulations come into force in April 2007 with the revised Approved Code of Practice released in January.

\section{Crane collapses}

A type BPR222 $50 \mathrm{~m}$ crane fell on a Battersea site killing two people, one of whom was a member of the public who was washing his car. Initial reports suggest that the crane boom became detached from the mast and fell on to the homes and a parked car. This is the third crane accident in the UK in the past six years. The cause of crane failures (the cause of the Battersea failure has not been published) includes poor maintenance, misuse and lack of training and external factors including weather and ground conditions. 
- 2000 - three people killed in Canada Square Canary Wharf while the height of the Wolff $320 \mathrm{BF}$ luffing jib tower crane was being raised.

- 2005 - two people killed on a Worthing Schools project while the crane was being dismantled - The Health and Safety Executive (HSE) were unable to reach any firm conclusions as to the cause.

- 2006 - two people killed when a type BPR222 $50 \mathrm{~m}$ crane collapsed in Battersea. - 2006 - no deaths following partial collapse in City of London when the booms of two cranes collided.

Within the UK, the HSE estimates that there are about 1,000 tower cranes in use or available. It is estimated that the number of separate operations involving climbing frames has been around 60 per year. The increasing use of climbing frames for the erection of tower cranes probably reflects the number of 'high rise' buildings under construction, the decrease in available space to erect tower cranes by more traditional methods (such as the use of mobile cranes) and the cost of alternative methods.

\section{DILAPIDATIONS}

\section{Pre-action protocol for terminal dilapidations claims}

The Civil Procedures Rules (CPR) were introduced in 1998 and introduced the idea of protocols for the conduct of parties before litigation was instigated. The aim of this procedure was intended to ensure that the support for a claim was provided at the commencement of an action so that the parties were in no doubt as to the reason and support for the contemplated action. The Pre-Action Protocol for claims for damages in relation to the Physical State of Commercial property at the end of a lease was issued in September. It replaces the draft introduced in 2000. The Department of Constitutional Affairs has not adopted this protocol, because, among other things, there is already a binding general protocol set out in the CPR practice direction.
It acknowledges that the circumstances of the case must determine the procedures to be followed and that as a result the protocol is not mandatory or intended to be an exhaustive list of the steps to be taken (1.4). The new protocol does, however, suggest that the Landlord's surveyor should provide a written endorsement that the Landlord's Claim is a fair assessment of the Landlord's Loss (4.8.3). The documents state that compliance with the protocol should enable both landlords and tenants to make an early informed judgment on the merits of their case (1.6).

The court is expected to treat the standards set out in the protocol as being the normal reasonable approach to pre-action conduct, so ignore it at your peril.

The Protocol states that the schedule should separate the breaches into relevant categories (eg, repair, reinstatement, redecoration) and these should be listed separately in the schedule. The schedule should be issued within 56 days of the end of the lease and the tenant should reply within 56 days.

The claim should set out what the landlord considers to be the breaches, the works required to be done to remedy those breaches and the landlord's costing (4.1) together with full details of any other losses (4.6). The claim should not include any items likely to be superseded by works to be carried out by the landlord or his or her intentions for the property (4.8.2). A formal quantification of the landlord's loss based on a formal diminution valuation or an account of the actual expenditure or combination of both must be provided by the landlord (4.8.5).

\section{Dilapidation loss could have been assessed by Judge}

Latimer and another $v$ Carney and others [2006] EWCA Civ 1417 Court of Appeal

In an appeal against a rejection of a claim for loss where the first instance judge had dismissed the claim because he felt that the claimant had failed to prove the actual costs of repairs, the Court of Appeal, in overturning that judgment, confirmed that Section 18 of the 1927 Act required the court to find the amount of the damage to the value of the reversion of the premises caused by the failure to repair. The court 
had to find the difference between the value of the premises in disrepair on the open market and what the value would have been in the absence of any breach of the covenant to repair. It need do no more than find that that difference was at least as great as the amount claimed against the tenant. In the absence of expert evidence, the judge should have inferred a diminution of value based on the estimated costs provided.

\section{EXPERT EVIDENCE}

\section{Meadows decision}

The Court of Appeal upheld the earlier High Court ruling that in giving ostensibly damning statistical evidence that he was not qualified to give, Sir Roy was not guilty of professional misconduct. The Court, however, agreed that such activity was capable of engaging the disciplinary attention of the GMC. The Court concurred that the GMC had the right to entertain complaints from members of the public relating to any of its members who acted as expert witnesses and gave flawed evidence.

\section{PROPERTY MANAGEMENT}

\section{Courts remind landowners of their need to inspect}

The High Court has considered the scope of the duty of care owed by landowners to users of public roadways adjoining their land. The Court's decision demonstrates that if trees lie alongside a public highway and the landowner has not taken steps to ensure that someone with specialist knowledge regularly inspects them, then the landowner may be liable. Mr Poll was injured when his motorbike was in collision with a fallen tree. Mr Poll successfully sued the owners of the land from which the tree fell for substantial damages on the basis of the landowner's alleged negligence in their care and management of the tree. The defendant's estate has many miles of boundary with public roads. This duty includes the inspection of trees anywhere upon your land to identify any potential hazard, but there is a particular need to inspect trees along side highways. Such inspections must be carried out by a competent inspector who would be able to identify the level of risk associated with a particular tree.

Gary Poll -v- Raymond Benedict Bartholomew Michael Viscount Asquith of Morley (1) and Mary Clare Bartholomew Viscountess Asquith of Morley (2) (11/05/06).

\section{Disabled accessibility action taken against Arcadia}

The Disability Rights Commission (DRC) is supporting a wheelchair user who is taking Arcadia to court after not being able to shop in her local Burton store because of a flight of steps. The store offered to bring goods to the customer at the shop entrance which she found unacceptable. The action against Arcadia is being taken under Part 3 of the Disability Discrimination Act (DDA), which requires shops and other businesses that provide services to the public, to take reasonable steps to remove physical barriers that make it unreasonably difficult for disabled people to receive a fair service or to provide reasonable alternatives to provide a non-discriminating service.

The Arcadia Group reported to the DRC that in February 2005 it had audited 50 per cent of its 2,500 stores in the UK for access. Of these, 40 per cent were physically inaccessible to disabled people. The Arcadia Group is the second retailer to be taken to court following new duties introduced in 2004 under the DDA. Last year the DRC supported an action against Debenhams. It is claimed that the action, if successful, will be crucial in spelling out what steps retailers need to take to meet their legal duties.

\section{VALUATION AND TAXATION}

\section{Real estate investment trusts tax regulation announced}

The government has published further regulations on Real Estate Investment Trusts (REITs) in respect of taxation and investors. The four regulations cover the consequences of breaching conditions set out in Part 4 of the Finance Act 2006, the information that must be submitted by the principal company of a group 
REIT to HM Revenue \& Customs; the application of Part 4 of the Act to joint ventures in which the REIT is involved; and administrative provisions relating to the deduction and accounting for tax when REITS pay its tax-exempt profits as distributions to shareholders.

A regulatory impact assessment for the introduction of the UK REIT regime was published in March 2006 and may be found at www.hmrc.gov.uk/ria. It is believed that the introduction of REITs next year is having an affect on the supply of investments into the market at the present time.

The Government published a consultation document at Budget 2004, 'Promoting more flexible investment in property: a consultation', which included a partial regulatory impact assessment. It remains the opinion of the Government that introducing a bespoke property investment vehicle will bring economic benefits to the UK property investment market and the wider economy. Poor liquidity was identified as one of the reasons to promote these changes.

This is deemed to be a reflection of the nature of property itself as an asset. The commercial property market is dominated by large investors and pricing and investment decisions are often determined by individual transactions among a small number of players. It was also recognised that there was a lack of choice for the small investor who could not afford a complete building. The treasury also hoped that the changes would lead to more efficient usage of property, and the reduction of instability in the market. The ability of investors to leave the market at short notice has, however, not been considered.

Real Estate Investment Trust (UK-REIT) would be

- a closed-ended company, resident in the UK, that is publicly listed on a Recognised Stock Exchange;

- required to separate out its income between taxable and non-taxable portions, referred to as 'ring fenced' (non-taxable) and 'non-ring fenced'. This would represent at least 75 per cent of the vehicle's activity by income and assets.

- (fully taxable); and

- also required to distribute at least 90 per cent of its ring fenced profits to investors and to withhold basic rate tax on these distributions. No shareholder who had beneficial entitlement to dividends would be allowed to control (either directly or indirectly) 10 per cent or more of the UK-REIT's share capital or voting rights. 